\title{
Sculpture for the body: Maria José Oliveira
}

\begin{abstract}
With this paper we intend to analyze a set of works by Maria José Oliveira that stand between the borders of Sculpture and Jewelry. Looking at the scale and the pieces, both assume a body to use them but being able to be autonomous. We prefer the designation "Sculpture for the body". They are mixed pieces, which play with our concept of interior versus exterior and presence versus absence of the body, getting into the path of the absurd. They are versatile objects that mold to the body, dressing and reconfiguring it.
\end{abstract}

Keywords: sculpture/jewelry, body, interior/exterior, presence/absence, the absurd
Volume 4 Issue I - 2020

Isabel Ribeiro DE Albuquerque

Professor of visual arts and design jeweler, University of Lisbon, Portugal

Correspondence: Isabel Ribeiro DE Albuquerque, Visual artist, Professor of visual arts and design jeweler, Graduation in Plastic Arts/Painting, University of Lisbon, Faculty of Fine Arts (FBAUL) Master in Art Theory (FBAUL), Member of Fine Arts Research and Studies Center (CIEBA), Portugal,

Email isadribeiro@yahoo.com.br

Received: October 15, 2019 | Published: February 20, 2020

\section{Introduction}

Maria José Oliveira has an extensive work which covers ceramics, painting, sculpture, objects and a core of work that's the object of this paper: Jewelry. This set of works has already been called as nonjewels by Cristina Filipe or were given the name of anti- jewelry by Sílvia Chicó. The name Textile jewelry is also known and it's the title given to the exhibit displayed in 1988 in the Artefacto 3. Labeling this work is not, at all, the purpose of the present paper. This question was answered by post-modernism and the hybridization of the genres, but to clarify the boundaries that could give an identity about the typological features of these artifacts. Maria José's work is difficult to define because drawing can be painting on paper or collage and painting is itself often tridimensional. Because the scale and the pieces presuppose a body which wear them, they can even be autonomous, it will be more appropriate to call this work as "sculpture for the body", a classification that results from the thought of the twentieth century artistic avant-garde positions and the proclaimed death of the artistic disciplines. ${ }^{1}$

\section{Sculpture for the body}

The starting point of the pieces object of this work is the raw canvas, natural materials as linen and cotton threads painted with clay and oxides. They are pieces that have to do with the poetic of the smoothness contrasting with the harshness of the metal, which is only perceived on the golden leaf applications and the screws. The work Inhabited Sculpture (Figure 1) sends us to a body both interior as exterior, an emptied body, as if the skeleton has been stripped and hanged. This concept was already presented by René Magritte, in Philosophy in the Bedroom (1966). In it Magritte paints a hanging dress as if the form, the body that once existed, was still in it. This idea of a skin or a skeleton that someone undresses can also be seen in Skelaton Dress (Figure 2) by Elsa Schiaparelli. This artist, influenced by surrealism and cubism, thought that fashion couldn't be disconnected from the contemporary plastic art, mainly painting. Merging fashion and some artist's art, whom she hired, she offered women a new dressing code.

Inhabited Sculpture or Body Ribs (Figure 3) that Maria José presents us hanging from the ceiling sends us to Eva Hesse work Right After (Figure 4). In it she questions the place of the work of art because her work is focused in the frontier between painting and sculpture. ${ }^{2}$

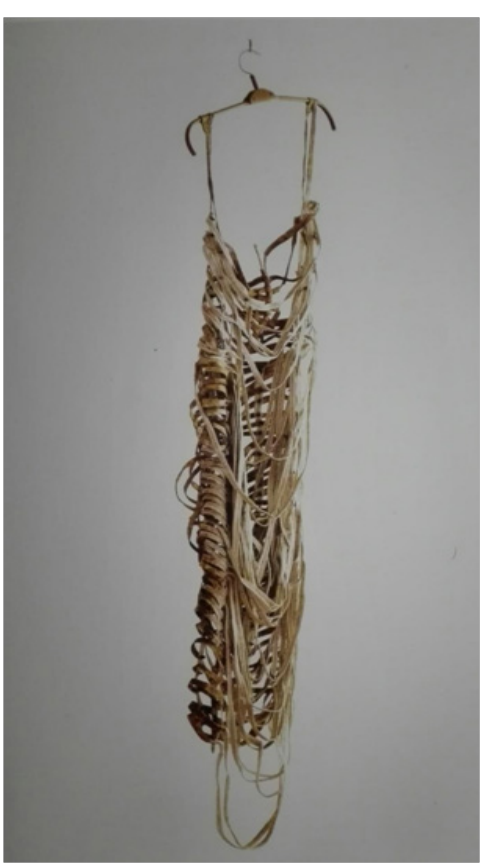

Figure I Oliveira MJ, Inhabited Sculpture, raw canvas gold plated and iron screws, with 63.0 I inches high, 1988. Col. Marie Hubber. Source: Ours.

The concept of a field of sculpture has been broadened since the sixties, whether referring to the techniques whether to the supports. In 1966, Lucy Lippard organized an exhibit with the name Eccentric Abstraction in which she included the work of Eva Hessa, admitting that the pictorial character of her work should be evaluated as sculpture. The same happens with Maria José's work that embraces contemporary jewelry as a way to create an identity because she wanted to create "things" she didn't know or that had not yet been named. While Eva Hasse (1936-1970) moves between minimalism or geometric abstraction and works in the transition between painting and sculpture, passing through the field of Eccentric Abstractionism, Maria José creates transition pieces with an unique character that we could classify as eccentric "formalism" since we can say that, in this work, she has never abandoned the form even if stripped of its interior. 
At the time many changes, both social and cultural, were happening and those reflected in the Art, particularly in jewelry which production no longer was a symbol of material wealth to become an open field to the experimentation: new ideas, new materials and techniques. In Holland, not only, "jewelry designs changed slowly from a traditional craft to a visual language, more or less connected to the human body". ${ }^{3}$ As an example, we have names such as Lam (Louise Antonia Maria) de Wolf (Figure 5) or Caroline Broadhead (Figure 6) whom in the eighties created pieces of textile jewelry to dress.

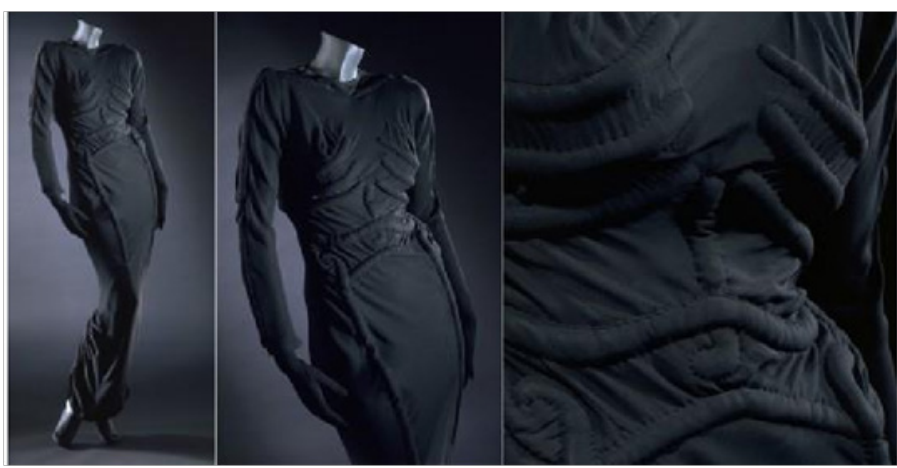

Figure 2 Elsa Schiaparelli, Skeleton Dress, to the Circus Collection in collaboration with the Surrealist painter Salvador Dali, evening gown, black velvet, 1930. Source: http://www.whokilledbambi.co.uk/2012/04/elsaschiaparellis-skeleton-dress/

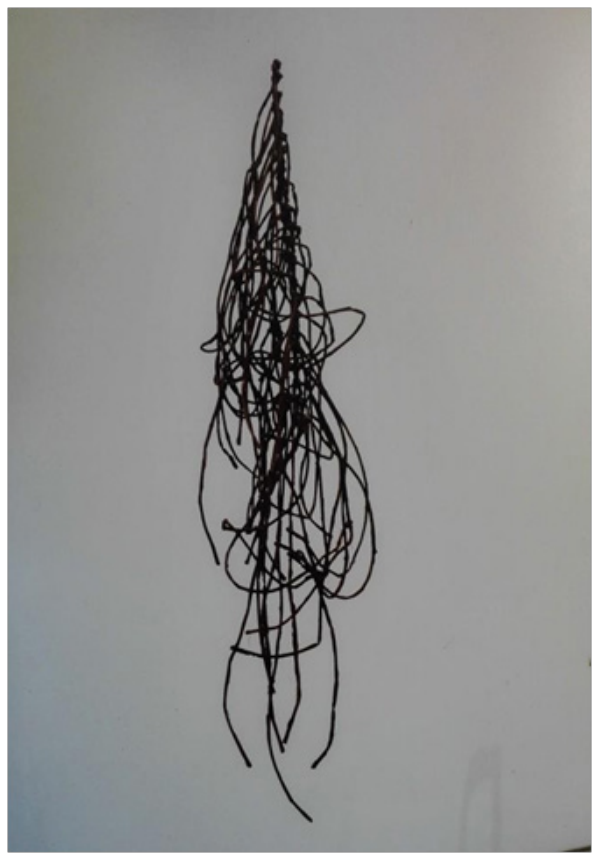

Figure 3 Body ribs, 1996, raw canvas painted with iron oxide, 27.56inches high. Source: Ours.

Contemporary jewelry has been acquiring significance because its creators value more the creative act rather than the process or the materials used traditionally, creating a complex relation among the piece and its holder.

Contemplating these type of artistic pieces, we can pose questions as: How was it created? How someone is going to wear it interpreting its meaning? What is its value?

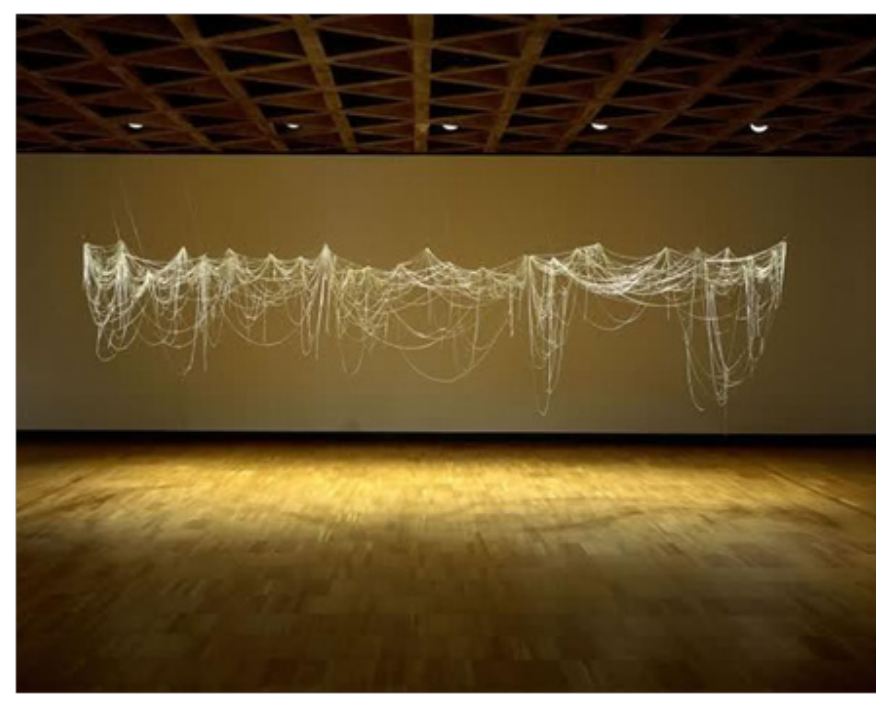

Figure 4 Right After, 1969, fiber glass, polyester, resin, wire, approximately: $5 \times 18 \times 4 \mathrm{ft}(152.39 \times 548.61 \times 121.91 \mathrm{~cm})$. Source: http://forums.thefashionspot. com/f8I/eva-hesse-sculptor-painter- 76/02.html

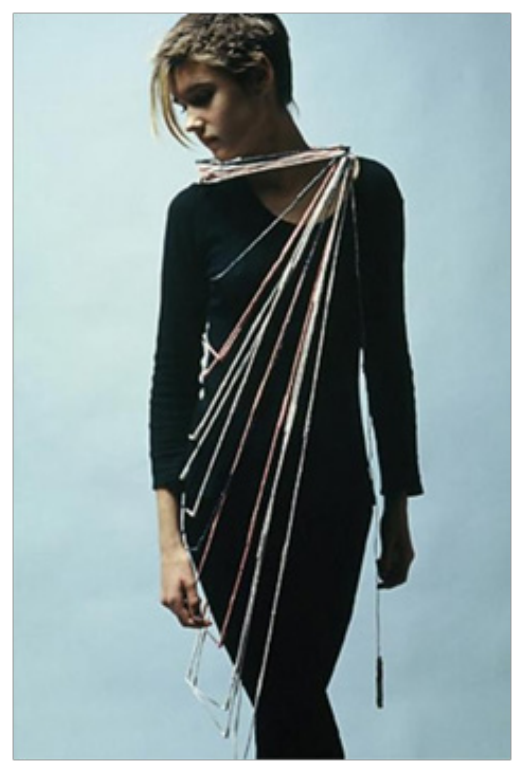

Figure 5 Lam de Wolf, 1982, Wearable object fabric and wood, 129×64×29cm Foto: TextielMuseum, photograph with model: Hogers and Versluys. Source: https://artjewelryforum.org/exhibition- reviews/body-jewels

Who is going to wear it? How the intentions of its creator will meet the expectations of the ones who will wear it. ${ }^{4}$ These questions are relevant in what concerns Maria José's pieces that explore the boundaries between jewelry and sculpture and also the limits between fashion and jewelry. Since the materials are primeval, its value has to do with the act of creation, as is the case with any artistic object, and not with the intrinsic value of the materials. However, there are pieces that are thought not to be wear by anyone as is the case of the tunic which M. J. Oliveira created for the exhibit Looking for Maria, regarding the 300years of The Patriarchate of Lisbon and the 100years of Fatima Sanctuary (Figure 7). The work was conceived to put on one of the walls of the sacristy of Our Lady of the old Conception church, which stands in Alfândega Street, in Lisbon. The tunic displayed on a 
hanger, made of trip and wrapped in another tarlatan tunic, evokes the mystery of the Ascension by the absence of the body in the undressed and because it suggests the existence of a body in the sacred realm.

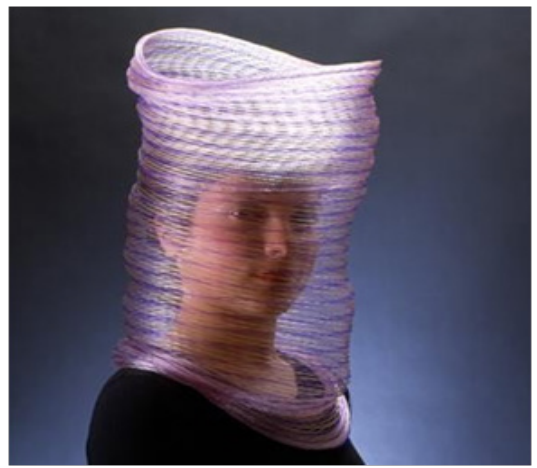

Figure 6 Caroline Broadhead, Colar Veil, 1983, nylon, $60 \times 30 \times 30 \mathrm{~cm}$. Source: https://www.winterson.co.uk/blog/2013/06/five-minutes-with-carolinebroadhead-csm/

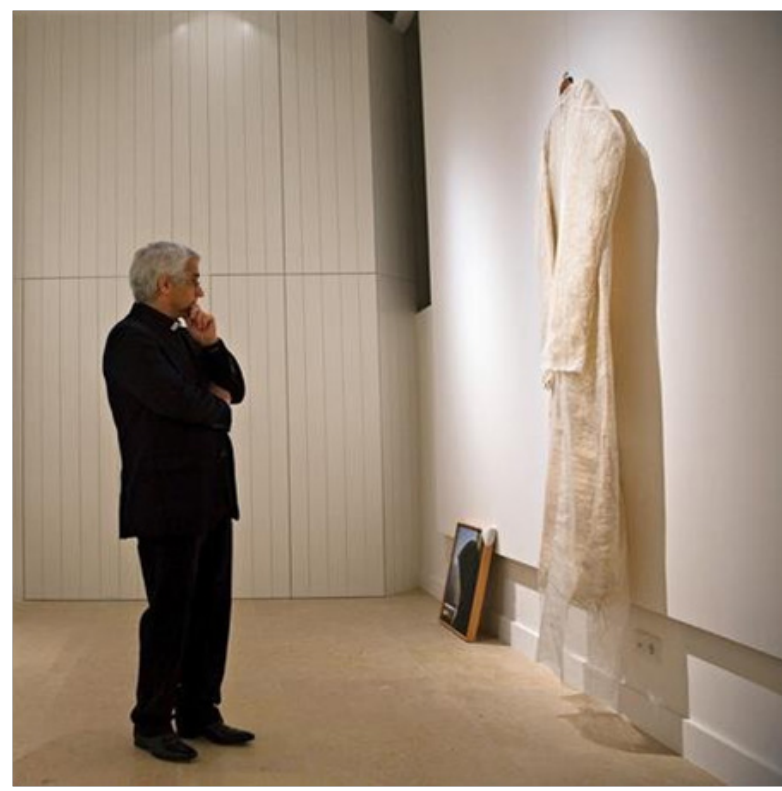

Figure 7 Looking for Maria, 2017, trip, hemp, cotton and tarlatan.

Source: http://circulodainovacao.pt/cultura/2016-I I-27-A-procura--de-Maria

This piece identifies itself with others of the same universe as is the case of the cow trip dress, Frida Kahlo waistcoat or Closer to You (2004), a blouse with just one very long sleeve in order to catch the other. There are objects which functionality is absurd on the formal logic plan; they play with the interior vs. exterior or with the presence vs. absence of the body.

Other pieces bring to the surface the interior of the body. We are not only talking of the Ribs and Vertebral column, but the Forearm (2014) made of raw canvas with a hook lock and brass hinges, simulating the muscle mechanic of the arm, through tubular elements which have in its interior a void that allows a real forearm to exist. It seems like the piece could be an interior layer to be used over the body. This idea of bringing the interior to the exterior can also be seen in the collars that were made from the inner material of a man's coat, in a game of textures: interlining, padded grey pulp, raw canvas and threads (Figure 8). Or another one more impressive that reminds us of an Egyptian headdress, in raw canvas and drawn with graphite which contains a rotating element (Figures 9\&10). We can add other fabric jewels, other collars and sleeve cuffs as fragments of clothing, or the Dura-Mater, or the Pia-Mater and the Arachnoid, which by their dimension, create a relation with the body that goes beyond the ornament, dressing it, reconfiguring it. ${ }^{5}$

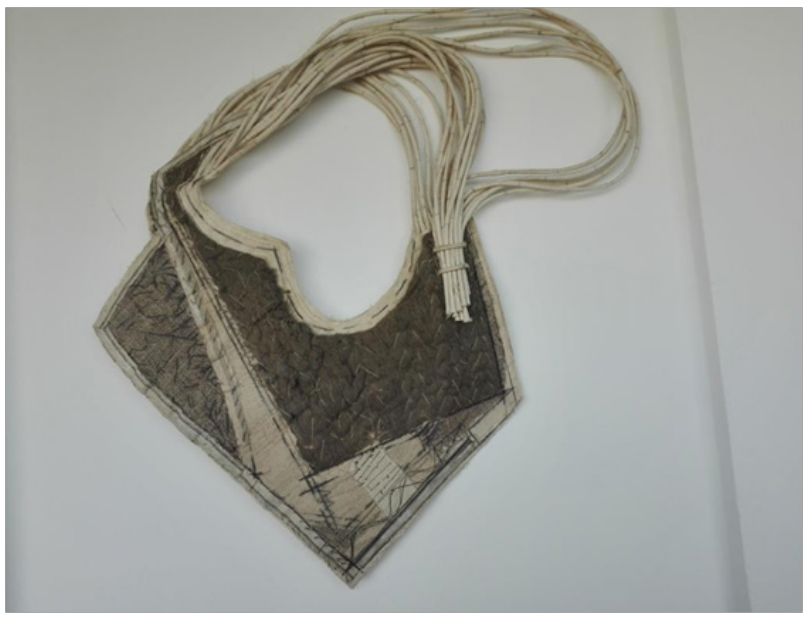

Figure 8 Collar, 1987/8, raw canvas, interlining, padded grey pulp, threads and graphite. Source: Ours.

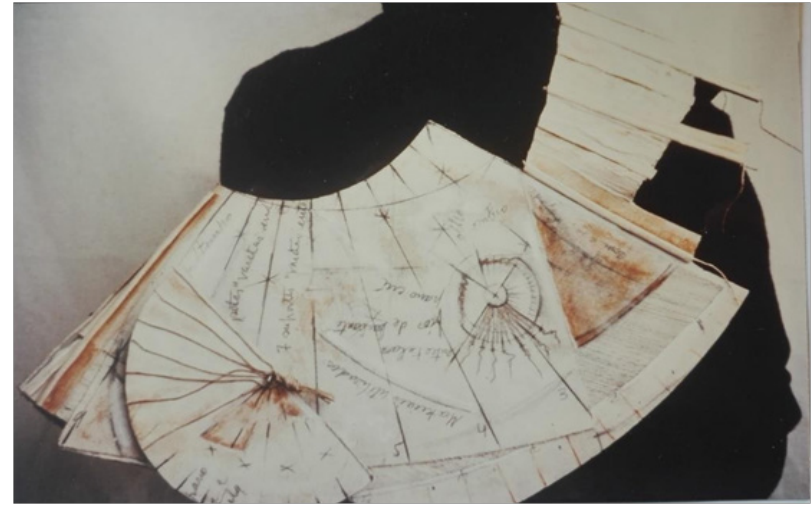

Figure 9 Collar (front), 1013, raw canvas, northern thread and graphite. Source: ours.

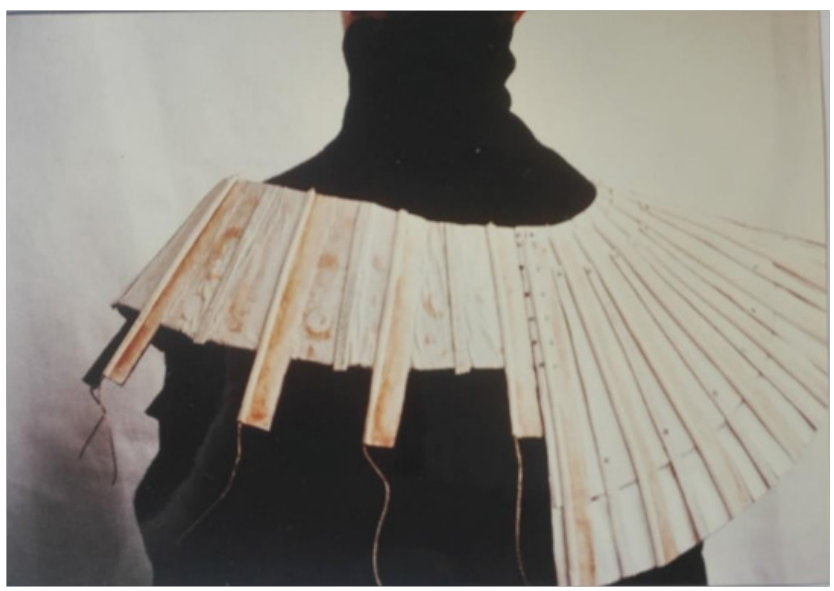

Figure 10 Collar (back), I0I, raw canvas, and graphite. Source: Ours. 
Finally, there is, yet, another aspect to consider which is the ludic perspective of the majority if these pieces in the sense they can be used in different ways. In some cases, they can be turned and the interior becomes the exterior. They are versatile ornaments that mold to the body and are never completely used, because they give different plastic images and each person can interpret of various ways, depending on the user and on the occasion.

\section{Conclusion}

Maria José Oliveira is an artist that crosses over all conceptual times of Art. Being indifferent to the traditional listings, she feels the materials and uses them to give substance to objects that happen to her as a result of her uneasiness and thought. These objects are the result of her restlessness and her thought. They are objects that she builds and shapes as soft sculpture and are related with the Esthetic of the Soft proposed by Claes Oldenbourg and continued by other artists as Ghada Amer with her embroidered drawings and paintings, or as the more recent sculptures of Louise Borgeois. Her work shows a huge sobriety mainly due to a limited color pallete that are predominantly constituted by the shades of ochre of oxides and clay and neutral shades of grey, black, white and the golden of the gold leaf applied here and there as a process of sacralization of the object. The primeval materials that she uses are also important, because they transform these objects in a paradoxal corpus of work, since that when they get into the field of jewelry their economic value is completely removed, concept attached to the traditional jewel and also because they are pieces which are addressed to a very special, unique public with ludic capacity. The main reason is because they are versatile and changeable pieces, which are subjected to various interpretations. They are original objects where the body is represented in layers as a second skin, of muscles or bones, through the des-occultation of the interior of the body or by using the clothes as a metaphor.

It is a work that operates permanently in the edge of the formal concepts, a work we can classify as mixed. A work in transition from a gender to another, that goes into the path of the unlimited experimentation through an eccentric formalism, with a very personal poetic. The forms that Maria José had been creating have a sculptural character and they are jewels when she intends them to be. It has been an innovator work in what the jewelry that was made in Portugal is concerned. It is a work contemporary of the New Jewelry which was taking the first steps in Europe and the United States. Maria José constructs and deconstructs from the body up to the entrails, whether using the entrails of a coat, trips, muscles or bones. From her work emerges an immense ontological interrogation and the endless artist anguish.

\section{Acknowledgments}

None.

\section{Conflicts of interest}

The authors declare that there is no conflict of interest.

\section{Funding}

None.

\section{References}

1. Sardo Delfim. The Experimental Exercise of Freedom: Art Devices in the $20^{\text {th }}$ Century. Orfeu Negro, Lisbon; 2017.

2. Kraus Rosalind. Bachlors, The MIT Press Cambridge. England: Massachusetts London; 2000.

3. Unger Marjan. News from the Netherlands. Calouste Gulbenkian Foundation, Lisbon. Dutch Form, Foundation, Amsterdam; 1990

4. Cheung Lin, Clarke Indigo, Clarke Beccy. New Directions in Jewelery II. London: Black Dog Publishing; 2006.

5. Godinho Ana, Filipe Cristina, Pinharanda João, et al. Maria José Oliveira, 40years of work. Documenta, Solar System, Lisbon; 2007. 